\title{
SEVERE HEAD INJURY ASSOCIATED WITH MULTISYSTEM INJURIES
}

\author{
Kalevski S., N. Peev, D. Haritonov, S. Dyankov \\ Department of Neurosurgery. Medical University - Varna, Clinic of Neurosurgery, \\ "St. Anna" District Hospital
}

Reviewed by: Assoc. Prof. R. Radev

\begin{abstract}
The incidence of severe head injury (SHI) varies between 20-30/100000. In the developed countries, the SHI contributes for over $50 \%$ of the dead outcomes among the trauma patients. Many investigations statistically prove that associated with SHI multisystem injuries negatively affect the outcome. In the present study we aim to investigate which organs and system having concomitant injury with SHI have a maximal negative influence to the outcome. We also aim to systematize the influencing factors, also to revise the treatment strategy. Our investigation is based on a cohort of 57 consecutive patients with dead outcome admitted to "St. Anna" Hospital for the period 2004 - 2006 year. The patients are classified according the localization of the associated injuries. A clinico-therapeutic classification was also made based on the severity of the patient's condition, also according to the necessary urgent management.
\end{abstract}

Key words: severe, head, multisystem, injury, classification, management, outcome

\section{INTRODUCTION}

The incidence of severe head injury (SHI) varies between 20-30/100000. In the developed countries, the SHI contributes for over $50 \%$ of the dead outcomes among the trauma patients $(2,5,13)$. In the USA $25 \%$ of all hospitalized trauma patients are patients with SHI. Furthermore over $60 \%$ of the dead outcomes among trauma patients in the hospitals is related to SHI $(2,16)$.

Many investigations statistically prove that associated with SHI multisystem injuries negatively affect the outcome (4). In recent days multiple factors and mechanisms that are involved in the secondary brain damage were identified (11). The majority of them are as a result of concomitant injury to other organs and systems, that specifically triger a chain of pathologic events that cause brain edema ischemia hypotonia, hypoxemia, hypercapnia, etc. $(2,5,11,15)$. In the present study we aim to investigate which organs and system having concomitant injury with SHI have a maximal negative influence to the outcome. We also aim to systematize the influencing factors, also to revise the treatment strategy.

\section{MATERIAL AND METHODS}

Our investigation is based on a cohort of 57 consecutive patients with dead outcome admitted to "St. Anna" Hospital for the period 2004 - 2006 year. On admission patients are with SHI - GCS $<8$ p. and concomitant injuries to other organs and systems.
Patient's records, imaging, perative protocols and pathologoanatomical findings are analyzed.In the investigated group $38(67 \%)$ are men and $19(33 \%)$ are women with mean age 49,5 (4-88).

In the first 24 hours $23(40 \%)$ of the patients died, while $15 / 23(65,2 \%)$ died due to asphyxia because of chest injury or aspiration of blood or gastric contents. The average hospitalization period is 6.33 days (0-84). Among the most common reasons for polytrauma are acceleration - deceleration - car accidents - 34 (59,6\%), falls from height - 15 $(26,3 \%)$, also everyday life trauma - $8(14,1 \%)$.

The patients are classified according the localization of the associated injuries, respectively "C" for cerebrum, " $T$ " for thorax, "A" for abdomen and "O" for orthopedic.

Tabl. 1.

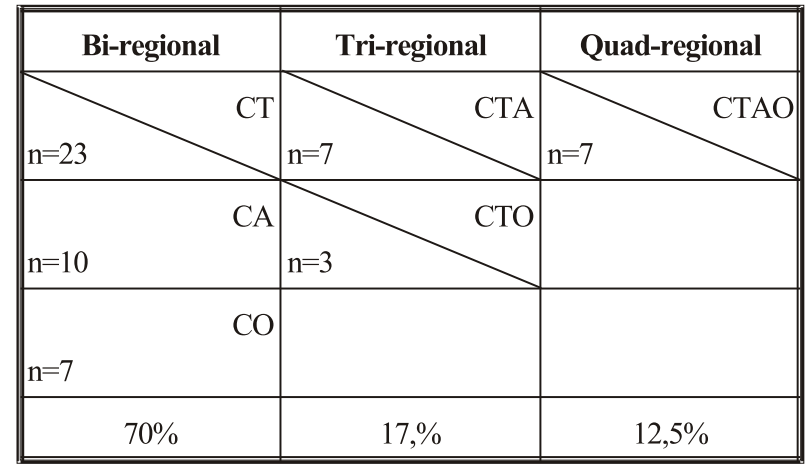

The most common are the bi-regional injuries - 40 cases (70\%): CT - 23; CA - 10; CO - 7; Next come the tri-re- 
gional - 10 cases $(17,5 \%)$ : CTA - 7; CTO - 3. Finally come the quadri-regional- CTAO - 7 (12,5\%) (Tabl.1.).

A clinico-therapeutic classification was also made based on the severity of the patient's condition, also according to the necessary urgent management.

I. Immediate - 24 cases with impaired vital functions necessitating imperious medical treatment - asphyxia, pulmonary aspiration, pneumothorax, haemothorax

II. Urgent - 21 cases that necessitated operative treatment within 1 hour after the trauma - massive intracranial haematomas, hemorrhages, etc.

III. Pressing - 7 cases that necessitated operative treatment within 4 hour after the trauma - fractures of big bones, acute ischaemias, ruptured internal organs, etc.

IV. Postponed - treatment procedures that are necessary but that could be postponed until the condition of the patient is stabilized - facial fractures, uretral ruptures, fractures of small bones etc.

The severity of the patient's condition is evaluated with GCS. Patients with GCS les than 8 are considered as SHI. All of the clinical diagnosis are confronted with the pathologoanatomical diagnosis and with the therapeutic approach.

\section{RESULTS}

In the investigated cohort of 57 cases, 23(40\%) died within the first 24 hours after the trauma due to ARDS following chest trauma, asphyxia, aspiration of blood or gastric contents, primary brain stem contusion. Between the first and seventh day died $30(52,6 \%)$ of the patients due to large brain contusions, severe brain edema, brain stem dysfunction, circulation or/and respiration failure.After the $15^{\text {th }}$ day died 4 with myocardial infarction or pulmonary trombembolism, etc.

In the followed cohort we found 30 combined fractures of the calvaria and the skull base, 13 skull base fractures, 6 calvarial fractures. In 8 of the cases the diagnostic imaging did not reveal scull fractures.

The CT-Scans revealed 32 massive supratentorial brain contusions, 21 brain stem contusions and 4 contusions of the pineal gland. All of the CT-Scan findings were subsequently confirmed with pathologoanatomical diagnosis. Managing the patients included in the present study we performed 27 craniotomies for evacuation of intracranial haematomas causing acute brain compression - Marshal type IV, extended hemorrhagic contusions, dislocated and causing brain compression skull fractures.

In $86 \%$ of the cases the neurosurgical interventions precede the surgical interventions treating trauma consequences in other organs and systems.In the rest of the cases the impaired vital functions are treated before the neurosurgical treatment.

The most common - 23 cases (40\%), are bi-regional associated lesions (CT) that require immediate treatment at the place of the accident, during the medical transportation, also in the emergency unit.

\section{DISCUSSION}

Manny authors emphasize a tendency of significant decrease of the mortality among the patients with SHI (8).However they often exclude patients with severe associated lesions, also these that reach the intensive care units with a big delay (14).

Kuhne et al. (6)study the dead outcome among the patients with SHI, so they found increased risk of mortality in the age above 55 years. This subgroup of patients has twice as big risk of multi-organ injuries if compare with the patients less than 55 years old.

In the group of patients that we investigated, $62 \%$ are in the age of 55 years, even though the patients that are less than 55 years old have more extended brain damage, also more severe associated multisystem lesions.

Tepas et al.(12) attribute the increased mortality among the elderly patients to the concomitant morbidity.

Based on this some authors $(1,4,7)$ create prognostic models, finding relation between factors as age, GCS, CT, associated lesions, arterial hypotension, intracranial hypertension, coagulopathy, etc. on the one hand and mortality on the other.

It is noticeable that in the group that we investigated $40 \%$ died within 24 hours and almost all SHI cave been combined with chest trauma or asphyxia. The period of the first 24 hours after the trauma is the most important period for the injured patients. It is comprised of prehospial resuscitation, stabilization of the vital parameters, diagnostic process in emergency care unit, neurosurgical procedures followed by admission in intensive care unit. Hence, it is extremely necessary a complex clinical-therapeutic plan for treatment of patients with SHI to be worked out. Furthermore it should include the whole period of treatment from the place of the accident to the admission in the specialized clinic.

Respecting the management of SHI, two main methodologies that present the modern conventional good medical practice, were published in the last 10 years - the European (EBIC) (10) and the American (Brain Trauma Foundation) (3).

Regardless some unessential differences, we also support the idea that the neurosurgical evaluation and specific treatment should be started immediately after the vital functions are stable. The complex treatment of these patients should be put in to practice by well trained team under supervision of neurosurgeon following appropriate algorithm.

\section{CONCLUSION}

1. Stabilization of the vital functions should treating the patients with SHI and associated multisystem injuries be considered should be considered as an absolute priority.

2. The treatment of such patients should be done in specialized for intensive care units by well trained teams under supervision of neurosurgeon. 
3. Regardless of the severity of the injury, patients in the age over 55 years have increased risk of dead outcome if compare to the patients under 55 .

\section{REFERENCES}

1. Boto GR, Gomez PA, De La Cruz J, Lobato RD. Severe head injury and the risk of early death. $J$. Neurol. Neurosurg. Psych. 2006; 1:1-11.

2. Bowman SM, Martin DP, Sharar SR, Zimmerman FJ. Racial disparities in outcomes of persons with moderate to severe brain injury. Medical Care 2007; 45(7):686-690.

3. Bullock R, Chesnut RM, Clifton G, et a 1. Guidelines for the management of severe head injury. J. Neurotrauma 1996;13:643-734.

4. Cremer OL, Moons KGM, van Dijk, Gert W, van Balen P, Kalkman CJ. Prognosis following severe head injury: devolpment and validation of model for prediction of death disability, and functional recovery. The Journal of Trauma Injury, Infection, and Critical Care 2006; 61(6):1484-1491.

5. Finfer SR, Cohen J. Severe traumatic brain injury. Resuscitation 2001; 48:77-90.

6. Kuhne CA, Ruchholtz S, Kaiser GM, $\mathrm{N}$ a s t-Kolb D, Working group of multiple trauma of the German society of trauma. Mortality in severely injured elderly trauma patients-when does age become a risk factor. World J. Surg. 2005;

29:1476-1482.

7. Lannoo E, Van Rietvelde F, Colardyn F, et a1. Early predictors of mortality and morbidity after severe closed head injury. J. Neurotrauma. 2000; 17:403-414.
8. Lu J, Marmarou A, Choi S, Maas A, Murray G, Steyerberg EW. Mortality from traumatic brain injury. Acta Neurochir suppl 2006; 95:281-285.

9. Lupescu V, Davidescu HB. Traumatologie-politraumatismele 2001; 2:183-212.

10. Maas A, Dearden M, Teasdale GM, et a 1. EBIC-guidelines for management of severe head injury in adults. Acta Neurochir. 1997;139:286-94.

11. Noppens R, Brambrink AM. Traumatic brain injury in children-clinical implications. Experimental and Toxologic Pathology 2004; 56:113-125.

12. Tepas JJ, Veldenz HC, Lottenberg L. Elderly injury: a profile of tauma experience in the sunshine (retirement) state. J. Trauma 2000; 48:581-586.

13. Thurman DJ, Alverson Cl, Dunn KA, Guerrero J, Sniezek JE. Traumatic brain injury in the United States: a public health perspective. $J$ Head Trauma Rehabil 1999; 14(6):602-615.

14. Valadka AB, Robertson CS. Surgery of cerebral trauma and associated critical care. Neurosurgery suppl 2007; 61(1):203 - 221.

15. Wang MC, Temkin NR, Deyo RA, Jurkovich GJ, Barber J, Dikmen S. Timing of surgery after multisystem injury with traumatic brain injury: effect on neuropsychological functional outcome. The Journal of Trauma Injury, Infection, and Critical Care 2007; 62(5):1250-1258.

16. Zulu BMW, Mulaudzi TV, Madiba TE, Muckart DJJ. Outcome of head injuries in general surgical units with an off-site neurosurgical service. International Journal of the Care of the Injured 2007; 38:576-583. 